
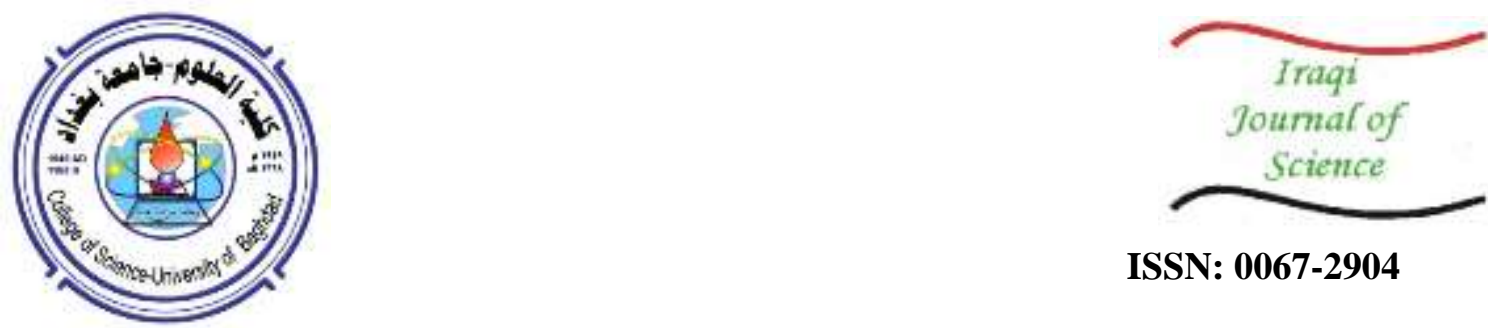

ISSN: 0067-2904

\title{
Scavenging of Free Radicals Generated in Biological Tissues Exposed to Ionizing Radiation Using Silver Nanoparticles
}

\author{
Asia H. Al-Mashhadani, Omar Salah Ashour
}

Department of Physics, College of Science, University of Baghdad, Baghdad, Iraq

\author{
Received: 24/6/2019 \\ Accepted: $17 / 5 / 2020$
}

\begin{abstract}
Humans are exposed to nuclear radiations every day, and these radiations are both natural and artificial. When the body tissues are exposed to nuclear radiation, free radicals are formed, which are responsible for cancer development. In this research, silver nanoparticles were synthesized by electrical explosion wire method. Nanoparticles were added to deionized water that contained free radicals before and after exposure to gamma rays. The obtained results indicate that the silver nanoparticles have antioxidant potential through possessing free radical scavenging activity, as they can donate electron to free radicals and become neutralize. Then, these nanoparticles were injected to mice before and after their irradiation with gamma ray. The liver and kidney of the mice were shown to be unaffected by gamma irradiation.
\end{abstract}

Keywords: Scavenging the free radicals, nano silver, Decontamination.

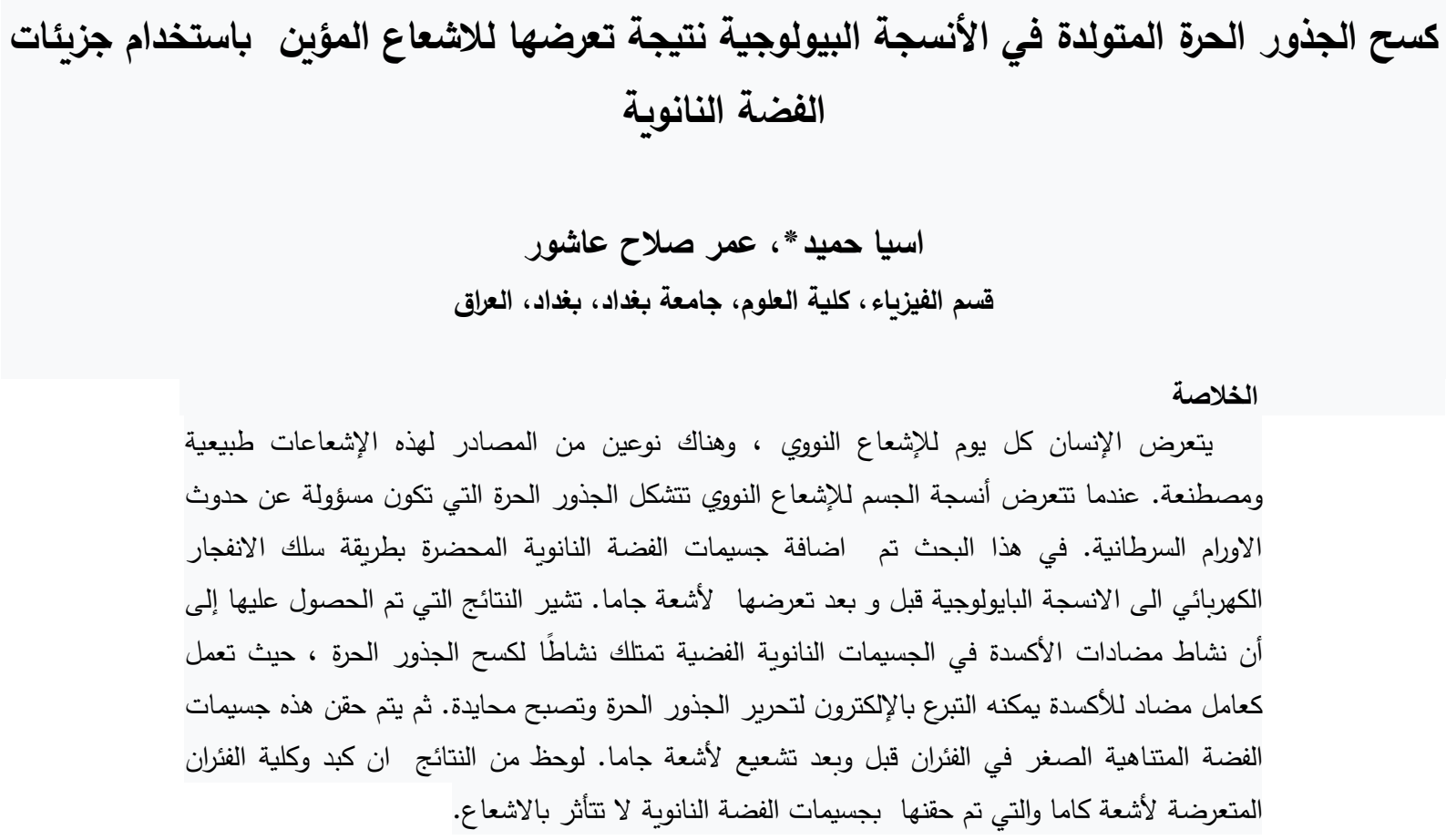

\section{Introduction}

Nanotechnology is unique in that it represents not just one specific area, but a vast variety of disciplines [1]. Nanoparticles are of great scientific interest as they bridge the gap between bulk materials and atomic or molecular structures [2]. Nanoparticles of noble metals, such as gold, silver, 
and platinum, are widely applied in products that directly come in contact with the human body. Thus, there is a growing need to develop environmentally friendly processes of nanoparticles preparation that do not use toxic chemicals [3].

Among the various inorganic metal nanoparticles, silver (Ag) nanoparticles received substantial attention for various reasons. Silver is an effective antimicrobial agent which exhibits low toxicity and has diverse in vitro and in vivo applications [4].

The inorganic nanoparticles are found to be effective in scavenging oxygen-based free radicals [5]. A free radical is defined as a molecular species capable of independent existence and contains one or more unpaired electrons [6]. Reactive oxygen species (ROS) are small, highly reactive, oxygencontaining molecules that are naturally generated in small amounts during the body's metabolic reactions and damage complex cellular molecules such as fats, proteins, or DNA [7]. The preparation of noble metal nanoparticles attracts an increasing interest due to their new and different characteristics as compared with those of macroscopic phase. This allows attractive applications in various fields such as antimicrobials, medicine, biotechnology, optics, microelectronics, catalysis, information storage and energy conversion [8]. Among all the known chemical and physical preparation methods, the exploding wire technique is one of the newest and simplest methods for producing metal nanoparticles [9]. The explosion is achieved when a very high current density is applied to a thin metal wire, causing the wire to explode to very small fragments. This process involves wire heating and melting followed by wire evaporation, formation of a high-density core surrounded by low-density ionized corona, coronal compression, and fast expansion of the explosion products [10]. The most effectively studied nanoparticles today are those made from noble metals, in particular Ag [11]. Applications of metal nanoparticles are distributed in various fields ranging from medical to physical fields [12-14].

Ionizing radiation is divided into direct and indirect ionizing for the understanding of its biological effects. Electromagnetic radiations, $\mathrm{x}$ and $\gamma$ rays, are indirectly ionizing because they do not produce chemical and biological damage [15].

Silver nanoparticles have a wide range of application in various fields from electronics to biology, pharmaceuticals to medical diagnosis and therapeutics to biosensor development [16]. There are many researches who have been studying the scavenging of free radicals and antioxidant activity of metals, such as gold nanoparticles [17] and cerium oxide nanoparticles [18]. Silver nanoparticles are the most important metal nanoparticles that may be utilized as free radical scavengers due to their inert properties and higher compatibility.

The aim of the present work is the use of silver nanoparticles for the scavenging of free radicals in the biological tissues and minimizing the radiation hazard occurring due to the formation of these free radicals which are responsible for tissue damage and further adverse effects in the human body .

\section{The experimental work}

In this work, deionized water was used as a sample for the study of scavenging of free radicals arising when water is exposed to different doses of ionizing radiation. The largest proportion of the human body $(75 \%)$ is composed of water. Ionizing radiation has severe impacts on the water and leads to the formation of free radicals. Water samples were irradiated by ${ }^{137} \mathrm{Cs}$ gamma source with $5 \mathrm{mCi}$ activity, which emits gamma ray with $662 \mathrm{keV}$ energy. The irradiation process was performed using the radioactive isotope cesium-137 by placing the radioisotope directly over the water or the animal. The radiative dose was calculated by our knowledge of the activity of the radioisotope.

The exposure rate in Rotengen/houre was calculated using the fallowing equation:

$$
\frac{x}{t}=\frac{\Gamma \times A}{d^{2}}
$$

where $\mathrm{X} / \mathrm{t}$ is the exposure rate, $\Gamma$ is gamma constant, $\mathrm{A}$ is tha activity of Cs-137, and $\mathrm{d}$ is the distance between the source and the samples.

Then the radiation dose rate D/t gray (Gy)houre ${ }^{-1}$ unit was calculated using the following equation:

$$
\frac{D}{t}=\frac{X}{t} \times a
$$

where a is a constant used to convert the exposure to absorbed dose in air. Then the radiation dose was calculated using the following equation:

$$
\mathrm{D}=\mathrm{D} / \mathrm{t} \times \mathrm{T}
$$


where $\mathrm{T}$ is the exposure time [19].

The irradiation was performed in the Department of Physics, College of Science, University of Baghdad. Rats were divided to six groups, each containing ten rats. Preparation of the silver nanoparticles was performed using the electrical explosion of wire (EEW) in $30 \mathrm{ml}$ deionized water with 10 explosions. In this method, a thin silver wire $(0.50 \mathrm{~mm}$ in diameter, $5 \mathrm{~cm}$ in length $)$ was used with a plate of $2 \mathrm{~cm}$ length, $1.5 \mathrm{~cm}$ width and $3 \mathrm{~mm}$ thickness. The absorbance of the silver nanoparticles was identified by UV-visible spectrophotometer at $403 \mathrm{~nm}$, as shown in Fig.1. The percentage inhibition of 2, 2-diethyl-1-Bicryl hydrazyl (DPPH) was calculated according to the following equation [20]:

Inhib. $(\mathrm{I} \%)=\left[\left(\mathrm{A}_{\text {ref }}-\mathrm{A}_{\mathrm{s}}\right) / \mathrm{A}_{\text {ref }}\right] \times 100 \%$

where $A_{\text {ref }}$ is the absorbance of irradiated water samples as a reference.

$\mathrm{A}_{\mathrm{s}}$ is the absorbance of samples with different concentration of silver nanoparticles.

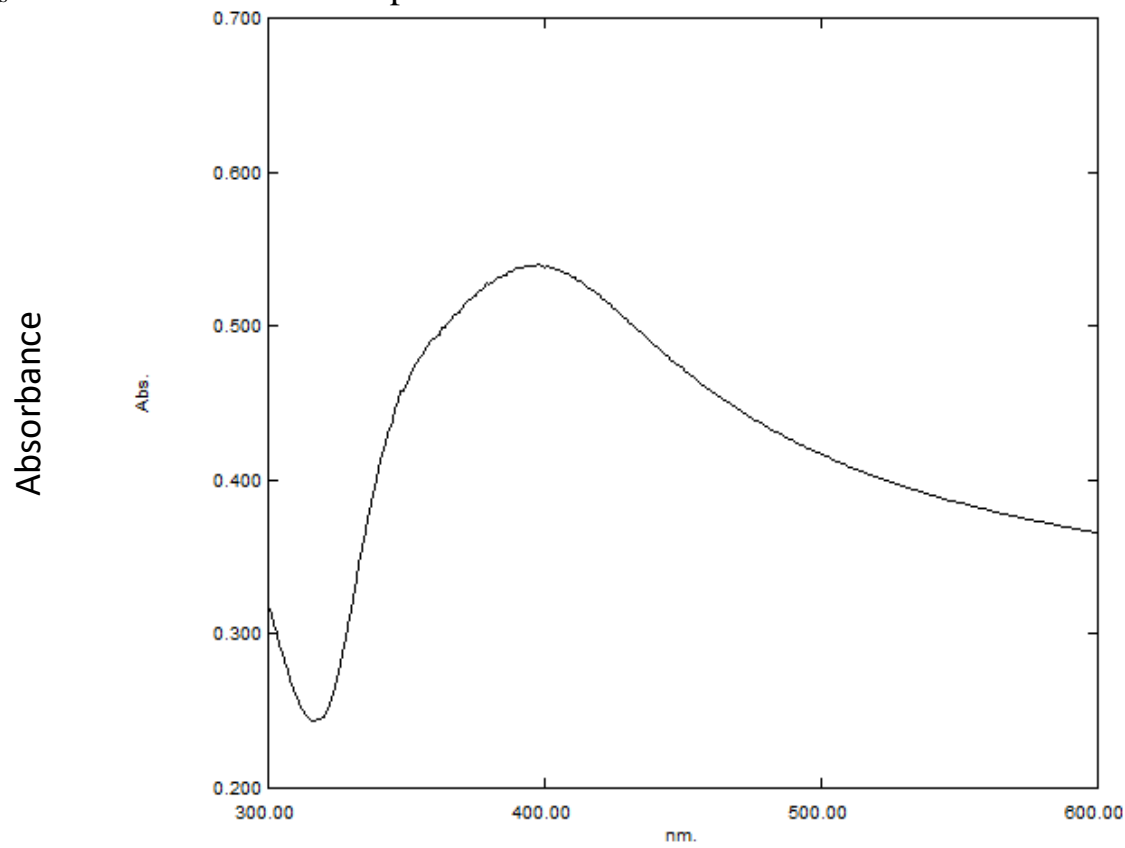

Figure 1-Absorbance of silver nanoparticles preparation by EEW around $403 \mathrm{~nm}$.

\section{Results and discussion}

\section{Antioxidant properties of nanoparticles}

A freshly prepared DPPH solution exhibits a deep purple color with a maximum absorption around $526 \mathrm{~nm}$. Various studies have been conducted to evaluate the antioxidant characteristics of different nanoparticles. However, this is the first time that nanoparticles with low concentrations are studied in relation to the decontamination of radiation (scavengers of free radical) formed in gamma irradiated water samples using DPPH assay.

\section{Silver nanoparticles as decontamination agents of radiation in vitro (phantom)}

The concentration of free radicals resulted by irradiation phantom with ${ }^{137} \mathrm{Cs}$ radionuclide was measured using DPPH material. The results of the in vitro decontamination (free radical scavenging) efficiency represented by the reduction of SPR of DPPH at $525 \mathrm{~nm}$ and the inhibition\% of free radical formation are shown in Figure-2.

In this experiment, silver nanoparticles with different concentrations were added to the deionized water samples, after irradiation with ${ }^{137} \mathrm{Cs}$, for the decontamination of radiation (free radicals formation). Figure-2 shows DPPH absorbance at $526 \mathrm{~nm}$ for all water samples with different concentrations of silver nanoparticles. 


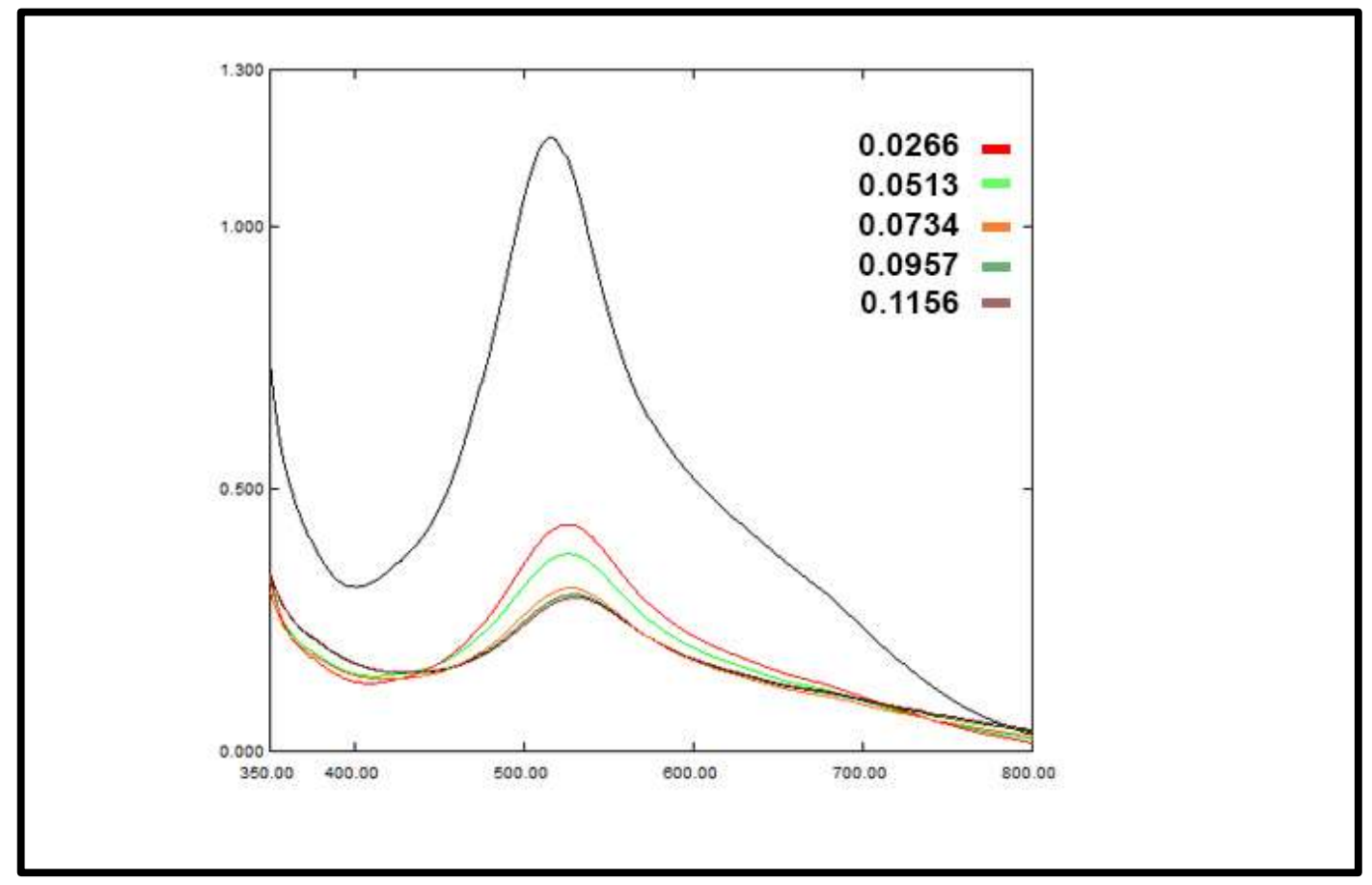

Wavelength (nm)

Figure 2- DPPH absorption for all water samples at $526 \mathrm{~nm}$ with different concentrations of silver nanoparticles (AgNPs).

Table-1 summarizes the values of DPPH absorption and free radicals scavenging (inhibition \%) for different AgNPs concentrations added after water irradiation.

Table 1-Values of DPPH absorption and inhibition \% for different concentrations of silver nanoparticles (AgNPs) added after irradiation.

\begin{tabular}{|c|c|c|}
\hline Water samples & DPPH & absorption \\
\hline $\begin{array}{c}\text { Irradiated water } \\
\text { nano silver concentration }\end{array}$ & 1.170 & Inhibition\% \\
\hline 0.0266 & Absorption & 63.00 \\
\hline 0.0513 & 0.432 & 67.86 \\
\hline 0.0743 & 0.376 & 73.41 \\
\hline 0.0957 & 0.311 & 74.44 \\
\hline 0.1156 & 0.299 & 75.00 \\
\hline
\end{tabular}

From this table, we can see that free radical concentration in the irradiated deionized water was 1.170 before adding the silver nanoparticles. Then, after adding $0.0266 \mathrm{~g} / \mathrm{l}$ AgNPs to the deionized water, the SPR of DPPH was 0.432 and the inhibition was $63.00 \%$. Moreover, after adding $0.0513 \mathrm{~g} / \mathrm{l}$ AgNPs, the SPR of DPPH became 0.376 and the inhibition was $67.86 \%$. After adding $0.0743 \mathrm{~g} / 1$ AgNPs to the deionized water, the SPR of DPPH became 0.311 and the inhibition was $73.41 \%$. Then, following the addition of $0.0957 \mathrm{~g} / 1$ of AgNPs to the deionized water, the SPR of DPPH was 0.299 and the inhibition of free radicals became $74.44 \%$. Finally, after adding $0.1156 \mathrm{~g} / \mathrm{l}$ of AgNPs to the deionized water, the SPR of DPPH became 0.293 and the inhibition became $75.00 \%$.

Figure-3 shows the absorption of DPPH was decreasing with the increase in AgNPs concentration to up to $0.1156 \mathrm{~g} / \mathrm{l}$. Accordingly, highest scavenging activity of AgNPs was noticed to be at the concentration of $0.1156 \mathrm{~g} / \mathrm{l}$, where the inhibition was $75 \%$, as shown in Figure-4. 


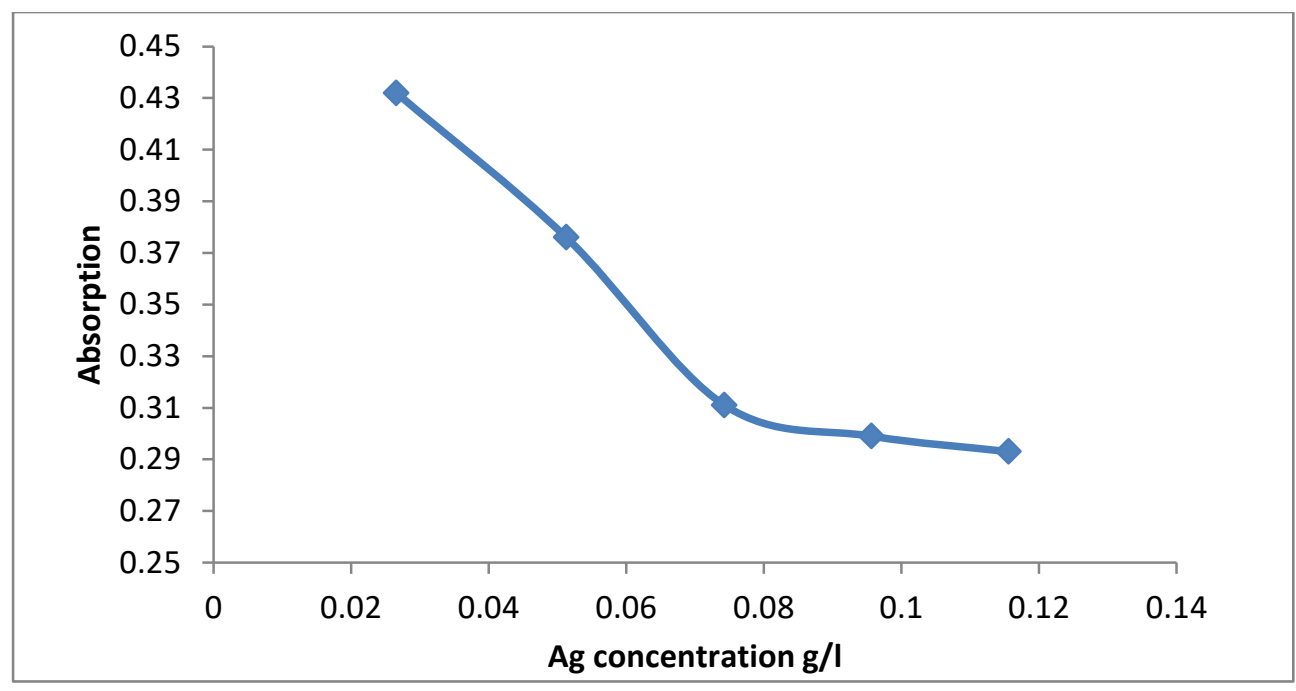

Figure 3-Absorption for all samples with silver nanoparticles (AgNPs) added to deionized water after irradiated with gamma ray as a function of sliver concentration.

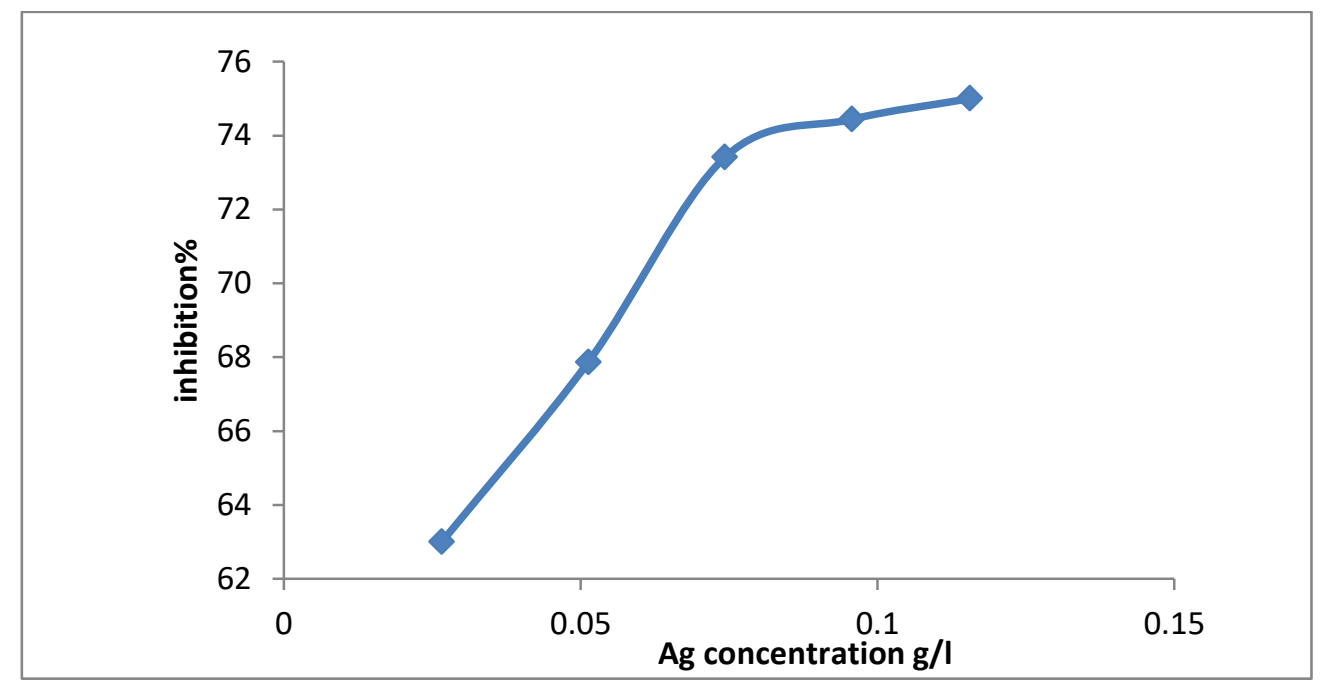

Figure 4- Inhibition\% for all samples with silver nanoparticles (AgNPs) added after irradiation deionized water as a function of silver concentration.

The obtained results indicate that AgNPs possess free radical scavenging activity, where they act as antioxidant agents that can donate electron to free radicals and become neutralized. After donating an electron, an antioxidant becomes a free radical by definition. Antioxidants in this state are not harmful because they have the ability to accommodate the change in electrons without becoming reactive. The unique properties of AgNPs such as high reactivity and the abundance of electron density enhance their ability in decontamination in water samples induce by gamma radiation. The most common ROS include the superoxide anion, hydroxyl radical, singlet oxygen, and hydrogen peroxide, which have unpaired electrons and can react with the antioxidant to prevent the oxidative stress. The impact of silver nanoparticles as an antioxidant occurs only within a limited range of concentration; further increase in the concentration leads to the formation of additional pollution (free radicals) due to a dual feature through the material. as the function as an oxidizer or an antioxidant is dependent on AgNPs concentration. Due to the larger surface area to mass ratio of smaller particles, more ROS could be formed than those in larger particles.

\section{Silver nanoparticles as decontamination agents of radiation in vivo}

The role of nanoparticles as radiotherapy is a cutting-edge development in decades of scientific interest regarding the therapy of normal cells and tissues from radiation. The chemistry of nanoparticles supports a potential role as a biological decontamination or antioxidant. The present work addressed the effectiveness of silver nanoparticles in radiotherapy of liver and Kidney cells of 
animal models during radiation exposure. This will encourage the development of innovative and new approaches to radiation therapy, using nanotechnology.

Histological analysis of the liver and kidney tissues of mice was carried out in Al-Nahrein University, Genetic Engineering Institute in order to examine the potency of silver nanoparticles to decontaminate the tissues from damages caused by free radical formation.

Figure- 5 shows the normal liver cells of mice. These normal mice were irradiated for 4 days, which is the same dose as that used to irradiate the deionized water.

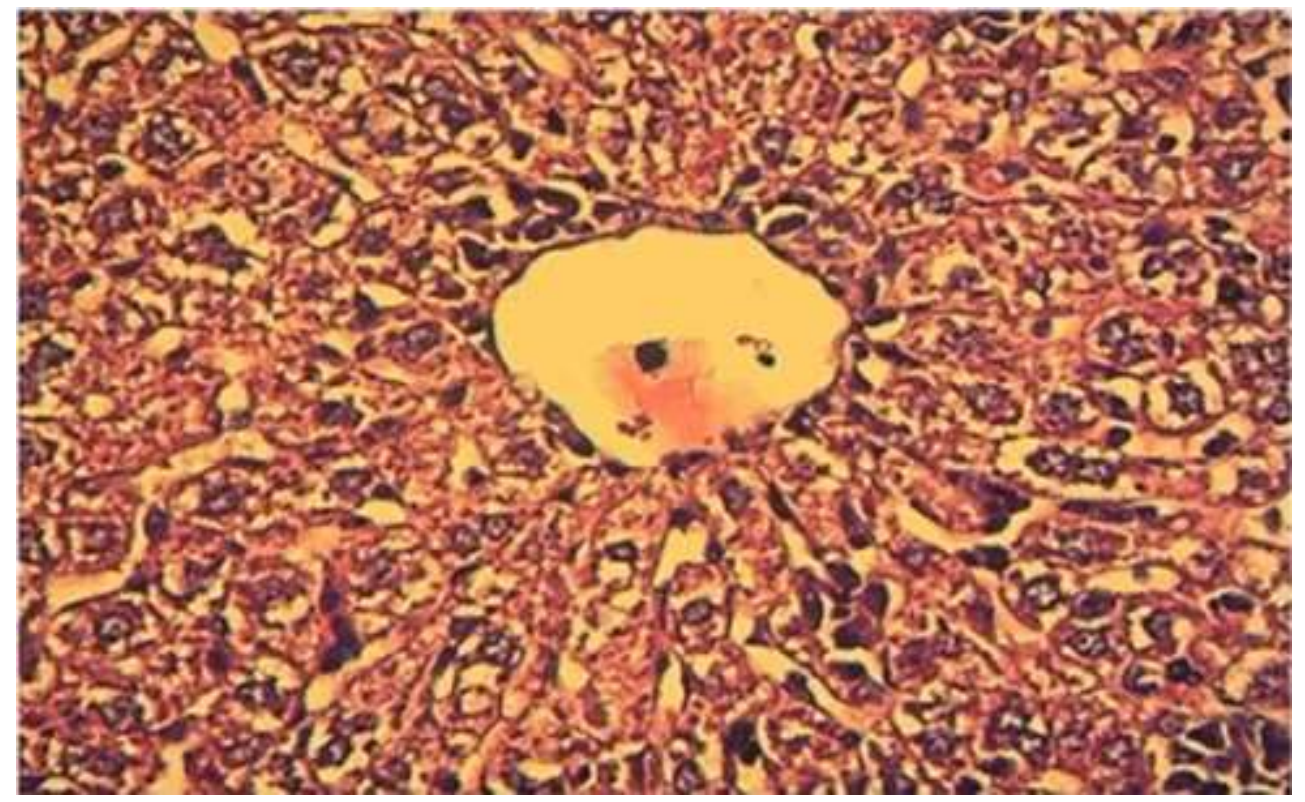

Figure 5-Histology of the liver of normal mice

Figure- 6 shows the development of congestion in the blood vessels of the liver lobes leading to the presence of acute inflammation in liver cells.

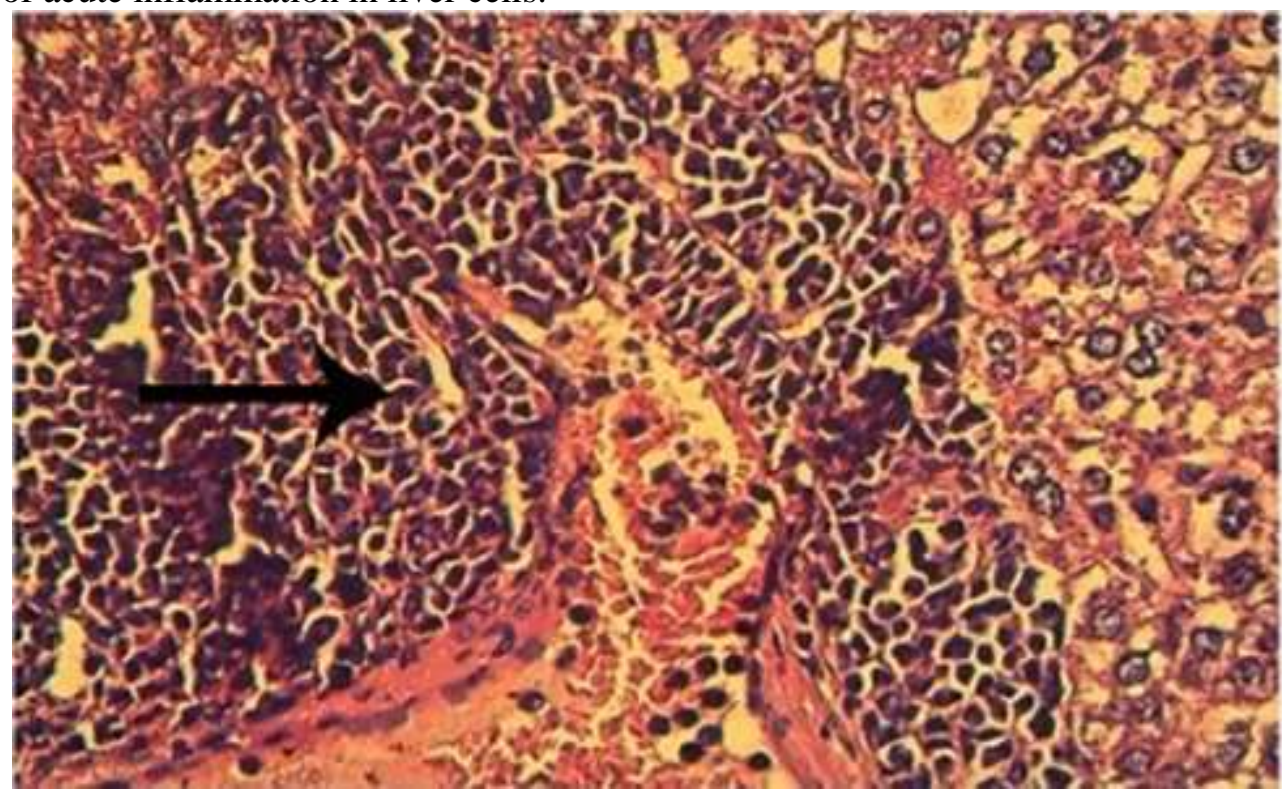

Figure 6- Histology of liver of mice exposed to a high dose of radiation.

But Figure-7 shows the liver cells of mice after injection them with AgNPs. This figure shows that the liver of mice was unaffected by gamma irradiation. 


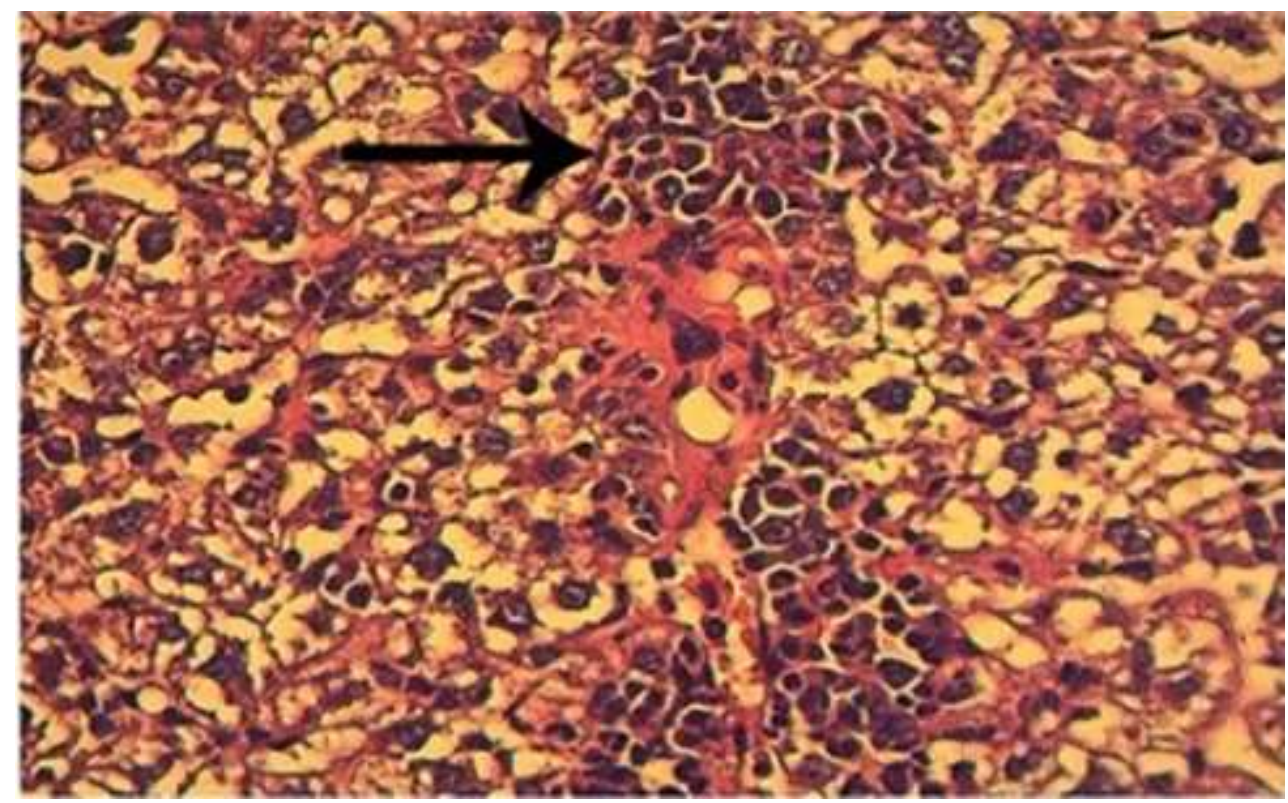

Figure 7-Histology of the liver of mice treaded with silver nanoparticles.

Figure- 8 shows the normal kidney cells of mice. When mice were irradiated, there was an enlargement in the area of the animal was existent when propping up the end of the upper ureter, as shown in Figure-9. Ionizing radiation was shown to have various effects on the kidneys of the rats, including the reduction of serum lipid profile, kidney function and glucose concentration. It was also shown to have significant free radical quenching effects and potent antioxidant activities against cardiovascular and kidney diseases.

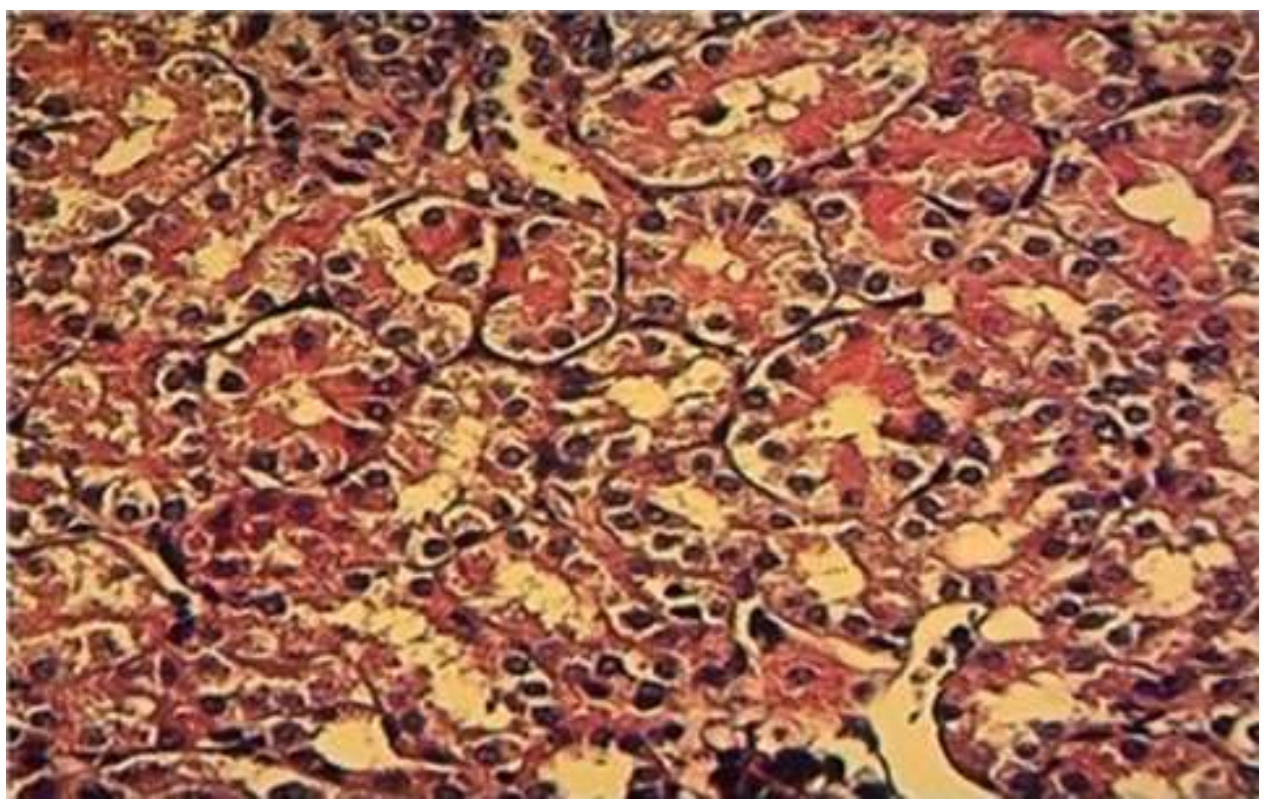

Figure 8-Histology of the kidney of normal mice. 


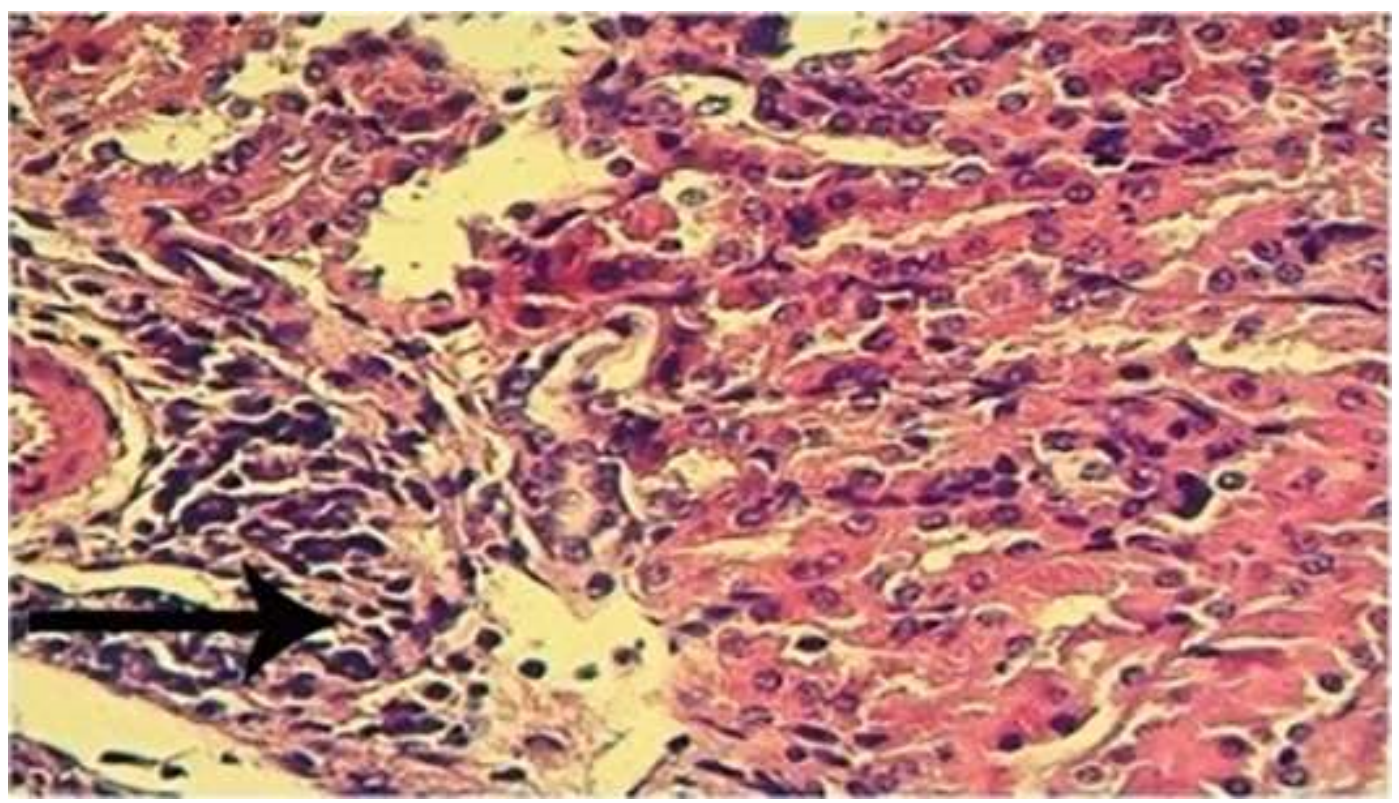

Figure 9-Histology of the kidney of mice exposed to a high dose of radiation.

The results showed that treatment with AgNPs caused the amelioration of the inflammation in the kidney tissue, as shown in Figure-10.

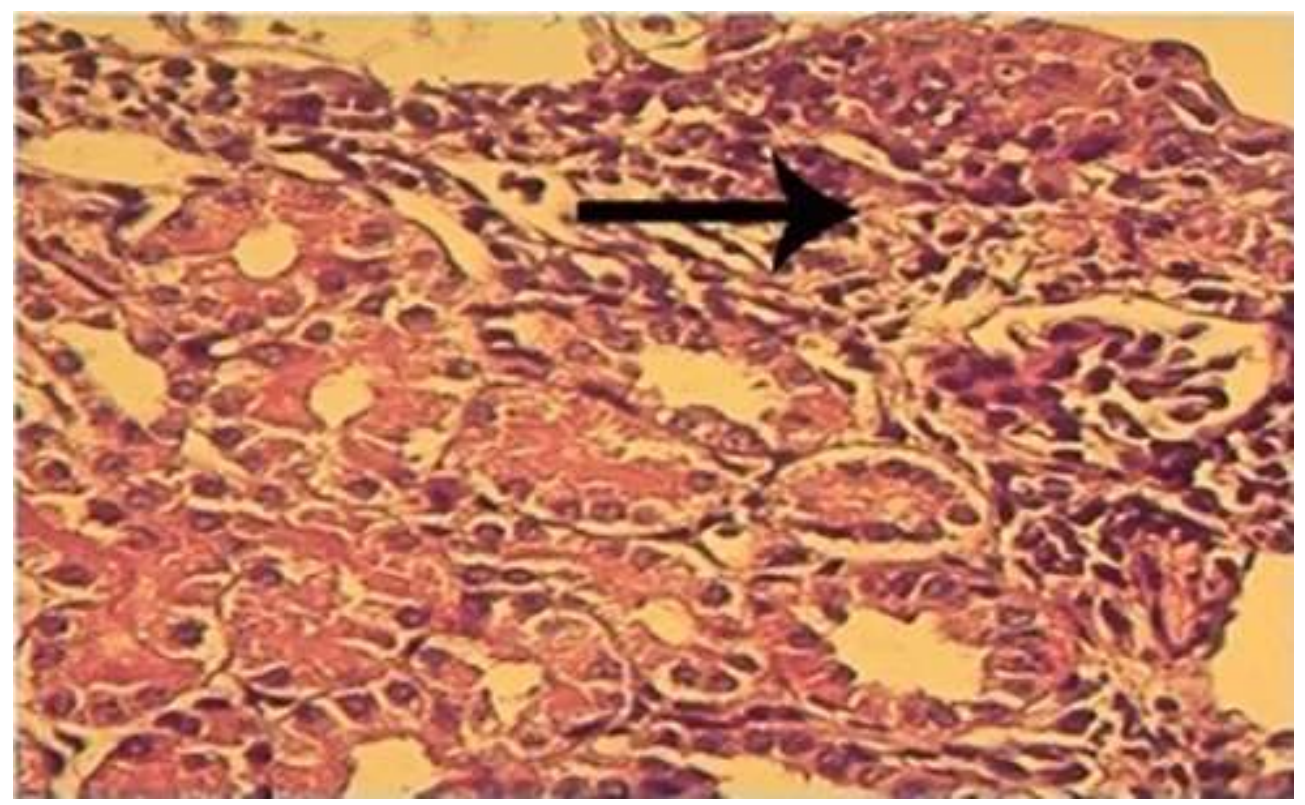

Figure 10- Histology of the kidney of mice treated with sliver nanoparticles.

\section{Conclusions}

There are many types of radioactive isotopes that are used in tumor treatment. One of the most important radioactive isotopes used in radiotherapy is ${ }^{60} \mathrm{Co}$. This can be used to treat tumors by delivering a dose of $\gamma$ ray (ionizing radiation). The uses of this radiation in controlling tumor growth induces also damages to other healthy cells, since it can penetrate easily deep into the tissues [21]. This research concludes that the effects of ionizing radiation on biological tissues can be reduced by pre-treatment of patients with a very small dose of silver nanoparticles.

The prepared AgNPs show a good antioxidant potential with a high activity of scavenging of free radicals. Therefore, they can be used to protect the human body from nuclear radiation. 


\section{References}

1. Putheti R.R, Okigbo R.N, Sai M.A. and Chavanpatil S. 2008. "Nanotechnology importance in the pharmaceutical industry", African J. Pure and Appl. Chem. 2: 27-31

2. Thakkar K.N., Mhatre S.S, Parikh R.Y. 2010. "Biological synthesis of metallic nanoparticles", Nanomed. Nanotechnol. Biol. Med. 6: 257.

3. Song J.Y., Jang H.K. and Kim B.S. 2009. "Biological synthesis of gold nanoparticle using Magnolia kobus and Diopyros kaki leaf extracts", Process Biochem. 44: 1133.

4. Farooqui M.A., Chauhan P.S. and Krishnamoorthy P., J. Shaik, 2010. " Extraction of silver nanoparticles from the leaf extracts of Clerodendrum inerme", Digest Journal of Nanomaterials and Biostructures, 5(43).

5. Babu S., Velez A., Wozniak K., Szydlowska J. and Seal, S. 2007. " Electron paramagnetic study on radical scavenging properties of ceria nanoparticles", Chem. Phys. Lett. 442: 405-408, (2007).

6. Ward R.F. and Peters T.F. 1995. "Free Radicals", Pearson Professional Limited, New York.

7. Wu D. and Cederbaum A.I. 2003. "Alcohol, oxidative stress, and free radical damage", Alcohol Res Health, 27(4): 277-284.

8. Kalaiselvi M., Subbaiya R. and Masilamani Selvam, 2013. "Synthesis and characterization of silver nanoparticles from leaf extract of Parthenium hysterophorus and its anti-bacterial and antioxidant activity", Int. J. Curr. Microbiol. App. Sci, 2(6): 220-227.

9. Sen P., Ghosh J., Alqudami Abdullah, Kumar P.and Vandana, 2004. Process and Apparatus for Producing Metal Nanoparticles, PCT International Appl. No. PCT/IN2004/000067, International Pub. No. WO 2004/112997, (2003) Indian Patent 840/Del/03, (2005) National Phase Entry in USA (filed).

10. Vandana and Sen P. 2005. "Nanometre scales surface modification in a needle-plate exploding system", J. Phys.: Condens. Matter, 17: 5327-5334.

11. Nelson Duran, Priscyla D Marcato,Oswaldo L Alves, Gaberiel IH De Souza and Elisa Esposito, 2005, "Mechanistic aspects of biosynthesis of silver nanoparticles by several Fusarium oxysporum strains", Nanobiotechnology, 3(8).

12. Sathyavathi R, Balamurali Krishna M, Venugopal Rao S, Saritha R and Narayana Rao D. 2010. "Biosynthesis of silver nanoparticles using coriandrum sativum leaf extract and their application in nonlinear optics", Advanced Science Letters, 3(2): 138-143.

13. Henley S.J., Carey J.D. and Silva S.R.P. 2006. "Silver-nanoparticle-decorated carbon nanoscaffolds: Application as a sensing platform", Applied Physics Letters. 89: 183120.

14. David D, Evanoff Jr and George C. 2005. "Synthesis and optical properties of silver nanoparticles and arrays", Chem Phys Chem, 6: 1221-1231.

15. Leela A. and Vivekanandan M. 2008. "Tapping the unexploited plant resources for the synthesis of silver nanoparticles"African Journal of Biotechnology, 7(17): 3162- 3165.

16. Mittal A.K, Kaler A.and. Banerjee U.C. 2012. "Free radical scavenging and antioxidant activity of silver nanoparticles synthesized from flower extract of rhododendron dauricum", Nano Biomed. Eng ., 4(3): 118-124.

17. Saritha K. and Saraswathi U. 2014 "Antioxidant activity of gold nanoparticles synthesized using Lemna minor" , World J Pharm Sci., 2(11): 1545-1551.

18. Soren S.,.Jena SR, L. Samanta and Parhi P. 2015. "Antioxidant potential and toxicity study of the cerium oxide nanoparticles synthesized by microwave-mediated synthesis", Appl Biochem Biotechnol., 177(1): 148-161.

19. Michael F. L'Annunziata. 2012. Radiation Physics and Radionuclide Decay, in Handbook of Radioactivity Analysis (Third Edition), ELESVIER, 2012

20. Omar S. 2019. "Decontamination of absorbed radiation in phantom using nanoparticles, and its applications in biological samples", MSc Thesis, College of Science, University of Baghdad, Iraq.

21. Kadhim A.A. and Essa, S.O. 2013. "Influence of the beam size radiation on the depth dose by using ${ }^{60}$ Co", Iraqi Journal of Science, 54(3): 607-611. 